\title{
Overexpressed IncRNA AC068039.4 contributes to proliferation and cell cycle progression of pulmonary artery smooth muscle cells via sponging miR-26a-5p/TRPC6 in hypoxic pulmonary arterial hypertension
}

\section{Yuhan Qin}

Southeast University Zhongda Hospital

\section{Boqian Zhu}

Jiangsu Province Academy of Traditional Chinese Medicine

\section{Linqing $\mathbf{L i}$}

Southeast University Zhongda Hospital

\section{Gaoliang Yan}

Southeast University Zhongda Hospital

\section{Dong Wang}

Southeast University Zhongda Hospital

\section{Yong Qiao}

Southeast University Zhongda Hospital

Bo Liu

Henan Provincial People's Hospital

\section{Erfei Luo}

Southeast University Zhongda Hospital

Jiantong Hou

Southeast University Zhongda Hospital

Chengchun Tang ( $\nabla$ tangchengchun@hotmail.com)

Southeast University Zhongda Hospital

\section{Research}

Keywords: IncRNA AC068039.4, miR-26a-5p, TRPC6, hypoxic pulmonary hypertension, PASMCs.

Posted Date: May 5th, 2020

DOI: https://doi.org/10.21203/rs.3.rs-25931/v1 
License: (c) (i) This work is licensed under a Creative Commons Attribution 4.0 International License. Read Full License

Version of Record: A version of this preprint was published at Shock on July 7th, 2020. See the published version at https://doi.org/10.1097/SHK.0000000000001606. 


\section{Abstract}

Background: Hypoxic pulmonary hypertension $(\mathrm{HPH})$ is a devastating and incurable disease characterized by pulmonary vascular remodeling, resulting to right heart failure and even death. Accumulated evidence has confirmed long coding RNAs (IncRNAs) are involved in hypoxia induced pulmonary vascular remodeling in HPH. The exact mechanism of IncRNA in hypoxic pulmonary hypertension remains unclear.

Methods冈Microarray analysis was applied to investigate the profiles of IncRNA expression in pulmonary artery smooth muscle cells (PASMCs) cultured under hypoxia and normoxia condition. qRT-PCR was performed for the expression of IncRNAs, miRNA and mRNAs, western blot analysis was employed for detection the expression of proteins. CCK-8 and transwell chamber assay were applied for assessment of PASMC proliferation and migration, respectively. Besides, flow cytometry was performed for assessments of cell cycle progression. The binding between AC068039.4 and miR-26a-5p, miR-26a-5p and TRPC6 3'UTR were detected by dual luciferase reporter assay.

Results凹A total of 1211 IncRNAs (698 up-regulated and 513 down-regulated) were differently expressed in hypoxia induced PASMCs. Consistent with microarray analysis, quantitative PCR verified that AC068039.4 was obviously up-regulated in hypoxia induced PASMCs. Knocking down AC068039.4 alleviated proliferation and migration of PASMCs and regulated cell cycle progression through inhibiting cells entering the G0/G1 cell cycle phase. Further experiment indicated AC068039.4 promoted hypoxic PASMCs proliferation via sponging miR-26-5p. In addition, transient receptor potential canonical 6 (TRPC6) was confirmed to be a target gene of miR-26a-5p.

Conclusion: In conclusion, downregulation of IncRNA AC068039.4 inhibited pulmonary vascular remodeling through AC068039.4/miR-26a-5p/TRPC6 axis, providing new therapeutic insights for the treatment of $\mathrm{HPH}$.

\section{Introduction}

Pulmonary hypertension $(\mathrm{PH})$ is an incurable disease with complex pathogenesis and characterized by over-proliferation, apoptosis resistance of pulmonary artery smooth muscle cells (PASMCs), pulmonary vascular remodeling (PVR) and elevated pulmonary vascular resistance, resulting in increased pulmonary arterial pressure, right heart failure and even death [1, 2]. It is convincing that over-proliferation of PASMCs is the pathophysiological basis of PAR and plays a vital role in the occurrence and development of $\mathrm{PH}[3]$. Hypoxic pulmonary hypertension (HPH) is a common cause of $\mathrm{PH}$ in multiple hypoxia and lung diseases, such as chronic obstructive pulmonary disease, interstitial lung disease, sleep disordered breathing and chronic exposure to high altitude[4]. Although clinical symptoms could be relieved under current treatments, no specifically effective treatments for HPH have been developed and disease progression remains inevitable[5]. Besides, no specific symptoms usually lead to delay in diagnosis and poor 
prognosis[6]. Therefore, further exploration of the pathogenesis of HPH is of great significance for finding novel effective treatments.

Based on the development of next-generation sequencing technology, a large amount of IncRNAs, longer than 200 nucleotides and incapable of protein transcription, have been identified exert their role in diverse biological process[7-9]. The "competitive endogenous RNA (ceRNA) hypothesis" indicates that IncRNA could sequestrate targeted miRNA and participate in miRNA regulation, indirectly involves in the regulation of miRNA-targeted genes[10]. The interaction between IncRNA and miRNA has been demonstrated in modulation of cell proliferation and apoptosis[11]. Previous studies have identified the role of several emerging IncRNAs, such as MEG3[12], LnRPT[13], Tug1[14], MALAT1[15], Hoxaas3[16], CASC2[17], are involved in the regulation of PASMCs proliferation, cell cycle progression and apoptosis of PASMCs and modulation of PVR. However, the role of IncRNA in HPH remains largely unknown. The current microarray analysis identified a significantly expressed novel LncAC068039.4.

Previous study demonstrated that miR-26a was down-regulated in both plasma from PAH patients and lung tissues of monocrotaline (MCT)-induced rats[18]. Store-operated calcium channels (SOCE) induced store-operated calcium entry (SOCE) is the main cause of calcium imbalance in PASMCs under hypoxia, transient receptor potential canonical 6 (TRPC6) is the main component of SOCC, up-regulated TRPC6 is related to PASMCs proliferation and PVR[19, 20]. TRPC6 also involves in PASMCs phenotype from contractile phenotype to the proliferative phenotype[21]. Previous study demonstrated IncRNAs may participate in regulation of TRPC6 expression [22].

Therefore, the current research aims to explore the role of IncRNA AC068039.4 in regulation of pathogenesis of $\mathrm{HPH}$. AC068039.4 was found up-regulated in hypoxia induced PASMCs, AC068039.4 interacted with and sponged miR-26a-5p, resulting to decreased degradation of TRPC6 and increased TRPC6 expression, ultimately contributing to over-proliferation of PASMCs. AC068039.4/miR-26a5p/TRPC6 axis might provide a novel therapeutic target for HPH treatment.

\section{Methods And Materials}

\section{Cells culture and ethics statement}

The Human PASMCs used in the experiment were isolated from the distal pulmonary arterioles in patients undergoing pulmonary lobectomy. This study was approved by the Medical Ethics Committee for Clinical Research of Zhongda Hospital (Nanjing, China). All subjects signed informed consent before the research. After removing the adventitia and intima of the pulmonary artery, the pulmonary artery smooth muscle was cut into small pieces of $1 \times 1 \mathrm{~mm}^{2}$, and then transferred to a culture flask. Isolated PASMCs were cultured in DMEM/F12 (Hyclone, CA) containing 10\% fetal bovine serum (FBS) (Gibco, San Diego, NY, USA), supplemented with $100 \mathrm{U} / \mathrm{mL}$ penicillin, and $100 \mathrm{mg} / \mathrm{mL}$ streptomycin in a humidified atmosphere containing $5 \% \mathrm{CO}_{2}$ at $37^{\circ} \mathrm{C}$. For hypoxic condition, PASMCs were incubated in the condition 
containing $1 \% \mathrm{O}_{2}, 94 \% \mathrm{~N}_{2}$ and $5 \% \mathrm{CO}_{2}$. 3-7 passages of PASMCs were used in the experiment. Cells were starved in serum-free DMEM/F12 medium for $24 \mathrm{~h}$ before all experiments.

\section{RNA interference, construction of the lentiviral vector and cell transfection}

Lentivirus encoding full length of AC068039.4 sequence, specific short hairpin RNA targeting AC068039.4 (sh-AC068039.4) tagged with Green fluorescent protein (GFP) and the negative control lentiviral vectors tagged with GFP were constructed by Genechem Co. (Shanghai, China). Recombinant lentiviral vectors noncoding miR-26a-5p mimic, mimic negative control (NC), miR-26a-5p inhibitor and inhibitor NC were also designed and synthesized by Genechem Co. to regulate the expression of miR-26a-5p. The sequences for each were listed in Table 1. The PASMCs were cultured in 6-well plates $24 \mathrm{~h}$ before transfection with a cell density of $70-80 \%$ and PASMCs were transfected following the manufacturer's introductions. Transfection reagents were removed after $24 \mathrm{~h}$, and the cells were further cultured in DMEM containing 5\% FBS. 3-4 days after transfection, fluorescence expression was observed using fluorescence microscopy and transduction efficiency was assessed by GFP expression $>80 \%$. PASMCs were collected used for subsequent experiments and shRNA with the best silencing effect tested by qPCR was used to perform the following experiment.

Table 1

Sequences of sh-AC068039.4, miR-26a-5p-mimic and miR-

26a-5p-inhibitor

\begin{tabular}{|ll|}
\hline Gene & Sequence (5'-3') \\
\hline shAC068039.4-1 & AGAACTACAAGGAGAAATA \\
\hline shAC068039.4-2 & CCACAATGCAATTATGTTA \\
shAC068039.4-3 & AATAATGCCATGTGTGAAA \\
miR-26a-5p mimic & UUCAAGUAAUCCAGGAUAGGCU \\
miR-26a-5p inhibitor & AGCCTATCCTGGATTACTTGAA \\
\hline
\end{tabular}

\section{Cell proliferation assay}

The cells were seeded in 96-well plate at a density of $5 \times 10^{3}$ cells per well, and $10 \mu$ l of CCK- 8 reagent (KGA317, KeyGEN BioTECH, Nanjing, China) was added to each well, then the cells were incubated in a $37^{\circ} \mathrm{C}$ incubator for 4 hours. A microplate reader (SYNERGY/H4, BioTek, USA) was used to detect the absorbance value of the cells at a wavelength of $450 \mathrm{~nm}(\mathrm{OD} 450 \mathrm{~nm})$ to analyze the proliferative activity.

\section{Cell migration assay}

Transwell Chambers (Corning, USA) was used to perform cell migration assay to evaluate the migration potential of PASMCs according to the manufacturer's introductions. The upper Transwell chamber, where 
PASMCs with different treatments were added, contains $0.5 \%$ FBS medium, while the lower chamber was filled with $10 \%$ FBS medium. After culturing for $18 \mathrm{~h}$, cells were washed with PBS and stained with crystal violet at room temperature for $15 \mathrm{~min}$ and then dried. A microscope was used for observation (Olympus, Japan).

\section{Cell cycle progression}

Cells were collected after trypsinization, centrifuged and resuspended in $1 \mathrm{ml}$ cold PBS. Then, cells were washed twice with PBS and fixed with precooled $70 \%$ ethanol at $4{ }^{\circ} \mathrm{C}$ overnight. The fixed cells were collected after centrifugation, and then resuspended in $500 \mu \mathrm{L}$ of staining buffer, $100 \mu \mathrm{l}$ of RNaseA was added, then add $25 \mu \mathrm{L}$ propidium iodide, the suspension was subjected to a water bath at $37^{\circ} \mathrm{C}$ for half an hour. Finally, the cells were filtered through a 400 mesh sieve, flow cytometry was used to detect whether the cells are in the G0/G1, S or G2/M cell cycle.

\section{Total RNA isolation and quantitative reverse transcription PCR}

Total RNA from PASMCs under different treatments was extracted with RNAiso Plus reagent (9109, TaKaRa, Shiga, Japan) according to the manufacturer's protocol. Nanodrop 2000 (Thermo Scientific, MA, USA) was used to measure concentration of RNA. Equal amounts of total RNA were reversed transcribed into cDNA using Prime-Script RT kit (RR047A, Takara, Japan). RT-PCR was performed with the TB GreenTM Premix Ex Taq TM II (RR820A, Takara, Japan) and Prism 7500 SDS (Thermo Scientific, MA, USA). The CT values of the target genes were recorded, relative gene expression was calculated using the $2^{-\triangle \Delta C T}$ method and $\beta$-actin or $U 6$ were used as internal references. Primers sequences are listed in Tables 2. 
Table 2

Sequences of the primers for quantitative PCR

\begin{tabular}{|c|c|}
\hline Gene & Sequence $\left(5^{\prime}-3^{\prime}\right)$ \\
\hline \multirow[t]{2}{*}{ IncRNA AC068039.4 } & Forward: GTGCCGAGATTGCAGCCTCTG \\
\hline & Reverse: AGACGCTCCTCACTTCCTAGACG \\
\hline \multirow[t]{3}{*}{ miR-26a-5p } & Forward: CGCGTTCAAGTAATCCAGGA \\
\hline & Reverse: AGTGCAGGGTCCGAGGTATT \\
\hline & RT Primer: GTCGTATCCAGTGCAGGGTCCGAGGT \\
\hline \multirow[t]{2}{*}{ TRPC6 } & Forward: CATGACGGCTTTAGAACTTAGC \\
\hline & Reverse: CTTCAGTGTTTCTGCACAGATC \\
\hline \multirow[t]{2}{*}{ PCNA } & Forward: GAAGGTGTTGGAGGCACTCAAGG \\
\hline & Reverse: GCAGCGGTAGGTGTCGAAGC \\
\hline \multirow[t]{2}{*}{ Cyclin A1 } & Forward: GGCACAGACCCAAAGCACACTAC \\
\hline & Reverse: AАCCTCCACCAGCCAGTCCAC \\
\hline \multirow[t]{2}{*}{ Cyclin D1 } & Forward: GCCCTCGGTGTCCTACTTCAAATG \\
\hline & Reverse: TCСТCСTCGCACTTCTGTTCCTC \\
\hline \multirow[t]{2}{*}{ Cyclin E1 } & Forward: GTGTCCTGGATGTTGACTGCCTTG \\
\hline & Reverse: CGCACCACTGATACCCTGAAACC \\
\hline \multirow[t]{2}{*}{$\beta$-actin } & Forward: GGCACCCAGCACAATGAAG \\
\hline & Reverse: CCGATCCACACGGAGTACTTG \\
\hline \multirow[t]{2}{*}{ U6 } & Forward: CTCGCTTCGGCAGCACA \\
\hline & Reverse: AACGCTTCACGAATTTGCGT \\
\hline
\end{tabular}

\section{Western blot analysis}

Cell total protein extraction kit (KGP2100, KeyGEN BioTECH, Nanjing, China) was used to extract total cellular proteins, and the protein concentration was measured using the BCA Detection Assay Kit (KGP902, KeyGEN BioTECH, China) according to the manufacturer's instructions. An equal amount $(20 \mu \mathrm{g})$ of the extracted proteins were subjected to electrophoresis on sodium dodecyl sulfate polyacrylamide gel electrophoresis (SDS-PAGE), and then transferred to a PDVF membrane (Millipore, Billerica, MA, USA). Membranes were blocked in TBST containing $5 \%$ non-fat milk for $1 \mathrm{~h}$ and incubated with primary antibody overnight. Antibodies used in the experiment included: anti-TRPC6 antibody (ab62461), anti-PCNA antibody (ab92552), anti-Cyclin A1 (ab53699), anti-Cyclin D1 (ab53699), antiCyclin E1 (ab133266) and anti-ACTIN antibody (ab8226) were purchased from Abcam (Cambridge, UK), 
the next day the PVDF membrane was incubated with a secondary antibody (Beijing TDY Biotech Co., Ltd., Beijing, China) for 1 hour. An ECL detection kit (GE Healthcare, UK) was used for blots visualization using and bolts were exposed with X-ray film.

\section{Dual luciferase reporter assay}

The AC068039.4 full length and wild-type (WT) 3'-UTR of TRPC6 were synthesized and cloned to pmirGLO Dual-Luciferase Vector (Promega, Madison, WI, USA). The predicted binding site was mutant as MUT-AC068039.4 and Mut-TRPC6. WT or MUT plasmid and miR-26a-5p mimics were co-transfected into Human embryo kidney 293 (HEK293) cells for $24 \mathrm{~h}$. Cells were harvested and the relative luciferase activity was determined by using a Dual-Luciferase Reporter Assay System (Promega).

\section{Microarray analysis}

Total RNA was extracted from PASMCs induced by hypoxia and controls, IncRNA microarray analysis was performed by Genechem Co. (Shanghai, China). The IncRNA microarray analysis identified 698 upregulated IncRNAs and 513 down-regulated IncRNAs in hypoxia induced PASMCs compared with PASMCs cultured under normoxic condition (fold change $>2.0$ and $P$ value $<0.05$ ).

\section{Statistical Analysis}

SPSS 22.0 software (SPSS, Chicago, IL, USA) was used for analysis. Data were expressed as mean \pm standard deviation. Independent sample student's t test was used for the comparison between two groups, and one-way ANOVA followed by Dunnett 's test was performed to evaluate differences among groups. $\mathrm{P}<0.05$ ( $\left.^{\star}\right)$ was considered statistically significant, $\left.\mathrm{P}<0.01{ }^{(\star *}\right)$ was regarded as highly significant difference. All experiments were performed at least three times.

\section{Results}

\section{Differentially expressed profiles of IncRNAs in normoxia and hypoxia induced PASMCs}

As shown in the schematic diagram in Fig. 1., microarrays analysis was used to capture the expression profile of IncRNAs in PASMCs cultured under normoxia and hypoxia. Hierarchical cluster analysis showed that the expression profiles of IncRNA in PASMCs induced by normoxia and hypoxia were different (Fig. 1A). Compared with the control group, a total of 1211 IncRNAs in PASMCs induced by hypoxia were significantly differently expressed (698 up-regulated and 513 down-regulated IncRNAs) (fold change > 2.0, $P$ value $<0.05$ ), indicating that these IncRNAs may be involved in the development of hypoxic pulmonary hypertension. In order to verify the reliability of the sequencing results, five significantly up-regulated IncRNAs and five down-regulated IncRNAs were randomly selected for quantitative real time PCR (qRTPCR) (Fig. 1B), and the results indicated that they were consistent with the microarray analysis experiment. The expression of IncRNA AC068039.4 in hypoxia induced PASMCs was significantly up- 


\section{LncRNA AC068039.4 was upregulated in hypoxia induced PASMCs and down-regulation of AC068039.4 alleviated hypoxia-induced proliferation and migration in PASMCs}

Previous studies have shown that hypoxia can promote PASMCs proliferation and migration. CCK-8 and transwell chamber analysis were used to investigate the effect of hypoxia on the proliferation and migration of PASMCs. As is shown in Fig. 2A, CCK8 assay analysis showed that after hypoxia exposure 0 , 24,48 , and 72 hours, PASMCs proliferation capacity increased in a time-dependent manner. Figure $2 B$ illustrated the transwell chamber analysis indicated that hypoxia significantly promoted the migration of PASMCs, which is also time-dependent. The results of microarrays analysis and PCR verification have shown that AC068039.4 is significantly up-regulated in hypoxia induced PASMCs. Figure $2 \mathrm{C}$ further clarifies the effect of different hypoxia exposure time on the expression of AC068039.4 in PASMCs. Quantitative PCR indicated that the expression of AC068039.4 increased significantly under hypoxic conditions. After 48 hours of hypoxia culture, the mRNA level of AC068039.4 was three times that of the normoxic control group. Lentivirus-mediated specific shRNA and lentivirus overexpressing AC068039.4 were synthesized and transfected into PASMCs to further clarify the role of AC068039.4 in hypoxiainduced proliferation and migration of PASMCs. Transfection with sh-AC068039.4 significantly decreased the expression of AC068039.4 mRNA and sh-AC068039.4-1 was used for further experiment for its best transfection efficiency. Transfection with lentivirus overexpressing AC068039.4 also effectively upregulated the AC068039.4 mRNA expression (Fig. 2D). Down-regulation of AC068039.4 could effectively reduce the proliferation potential of PASMCs and effectively reversed the hypoxia-induced hyperproliferation of PASMCs while overexpression of AC068039.4 could further promote PASMCs proliferation (Fig. 2E). In addition, Knockdown of AC068039.4 reversed the hypoxia-induced upregulation of PCNA protein expression in PASMCs, however, overexpression of AC068039.4 under hypoxia exposure further upregulated the hypoxia-induced PCNA protein level (Figs. 2F). Consistently with western blot analysis, qRT-PCR showed PCNA mRNA level significantly reduced after down-regulation of AC068039.4 and vice versa (Fig. 2G). In addition, the migration potential of PASMCs could be reduced after downregulation of AC068039.4, whereas upregulated AC068039.4 promoted PASMCs migration (Fig. 2H). These finding indicated that downregulation of AC068039.4 could alleviate hypoxia induced PASMCs over-proliferation and elevated migration potential.

\section{LncRNA AC068039.4 was involved in hypoxia-induced PASMCs cell cycle progression}

Flow cytometry was used to clarify the role of AC068039.4 in the regulation of cell cycle progression, it is clear that hypoxia can promote the cell cycle transformation from G0/G1 phase to $S+G 2 / M[23]$. 
Figure $3 \mathrm{~A}$ and $3 \mathrm{~B}$ indicated that down-regulation of AC068039.4 reduced the increased percentage of cells in the G2/M and S phases induced by hypoxia. In contrast, AC068039.4 overexpression increased the percentage of cells in the G2/M and S phase. Cyclin A/D/E are reported as key cell cycle proteins in $S$ and G2/M phases, and widely regarded as cell proliferation markers[24]. To determine the role of AC068039.4 on the regulation of cell cycle progression, western blotting and qPCR were performed to analyze the protein and mRNA expression levels of cyclin A1, cyclin D1 and cyclin E1. As illustrated in Fig. $3 C$ and 3D, both protein and mRNA levels of cyclin A1, cyclin D1 and cyclin E1 were reduced in PASMCs transfected with sh-AC068039.4 compared with negative control. Consistently, compared with negative controls, overexpression of AC068039.4 increased the expression levels of these proteins and mRNA. To sum up, these data indicated that AC068039.4 can promote cell proliferation through regulation of the cell cycle progression.

\section{LncRNA AC068039.4 promoted hypoxic PASMCs proliferation by interaction with miR-26a-5p}

miRNA screens of plasma from PAH patients and MCT-induced PH rats demonstrated that miR-26a was significantly downregulated compared to healthy controls. In addition, circulating miR-26a was identified as a novel biomarker candidate for PAH and closely correlated with 6-minute walk distance[18]. qPCR analysis was conducted to detect the expression of miR-21 in PASMCs and demonstrated that miR-26a$5 p$ significantly decreased as the hypoxia exposure time increased (Fig. 4A). Therefore, we investigated the effect of AC068039.4 on miR-26a-5p in hypoxia. qPCR analysis showed reduced miR-26a-5p expression caused by hypoxia can be partially reversed after PASMCs was transfected with shAC068039.4 and miR-26a-5p was further downregulated in PASMCs transfected with OE-AC068039.4 compared with negative control, suggesting that miR-26a-5p could be regulated by AC068039.4 (Fig. 4B). Dual luciferase reporter gene assay was performed after co-transfection of mimic NC and miR-26a-5p mimic with WT-AC068039.4 and MUT-AC068039.4. The gene sequence of WT and MUT-AC068039.4 were listed in Fig. 4C. Comparison to the mimic NC group, decreased luciferase activity was observed in cells co-transfected miR-26a-5p mimic and WT-AC068039.4, whereas no evident differences were detected when co-transfected miR-26a-5p mimic and MUT-AC068039.4, suggesting miR-26a-5p could bind to AC068039.4 (Fig. 4D). CCK8 analysis showed that the effect of inhibition of hypoxia induced PASMCs proliferation was counteracted after miR-26-5p transfection. Taken together, AC068049.4 could exert its role on hypoxia-induced PASMCs proliferation through regulation of miR-26a-5p.

\section{LncRNA AC068039.4 promoted hypoxic PASMCs proliferation through AC068039.4/miR-26a-5p/TRPC6 axis}

Previous studies have demonstrated TRPC6 plays a vital role in hypoxic pulmonary vascular remodeling and PASMCs proliferation and migration[25]. Figure 5A and 5B illustrated that both mRNA and protein level of TRPC6 significantly up-regulated in PASMCs exposed to hypoxia condition. As shown in Fig. 5C, the expression of TRPC6 protein decreased in PASMCs transfected with sh-AC068039.4, in contrast, up- 
regulated TRPC6 protein was found in PASMCs transfected with OE-068039.4. The expression of TRPC6 mRNA is consistent with TRPC6 protein expression after transfection with sh-AC068039.4 and OEAC068039.4 compared with negative control (Fig. 5D). Based on that AC068039.4 was involved in hypoxic PASMCs proliferation through interaction with miR-26a-5p, TRPC6 could be regulated by AC068039.4, we wonder whether miR-26a-5p exerted its role in regulation of hypoxia induced PASMCs proliferation through targeting TRPC6. Western blotting indicated the expression of TRPC6 protein decreased in PASMCs transfected with miR-26a-5p mimic compared with mimic NC, miR-26a-5p inhibitor could further up-regulated the expression of TRPC6 protein (Fig. 5E), which is consistent with qPCR (Fig. 5F). Dual luciferase report analysis was performed to confirm the interaction between miR-26a-5p and TRPC6. Bioinformatics prediction software showed that miR-425-5p had a potential binding site to the 3'-UTR of TRPC6 mRNA (Fig. 5G). Comparison to the mimic NC group, decreased luciferase activity was observed in cells co-transfected miR-26a-5p mimic and WT-TRPC6, cells co-transfected miR-26a-5p mimic and MUT-TRPC6 render unresponsive, suggesting TRPC6 is a target gene of miR-26a-5p (Fig. 5H). These data suggested that AC0689.4 may exert its biological role through the AC068039.4/miR-26a5p/TRPC6 axis .

\section{Discussion}

In this present research, microarray analysis was performed to search for differentially expressed IncRNA. Real-time PCR identified the significantly upregulated AC068039.4 in hypoxia induced PASMC, which might serve as a novel biomarker candidate in HPH. Downregulation of AC068039.4 inhibited proliferation and cell cycle progression of PASMCs. Combining prediction software with dual luciferase report analysis, AC068039.4 was detected to exert its role via sponging miR-26a-5p. Furthermore, miR-26 could bind to TRPC6 3'UTR, resulting in decreased degradation of TRPC6 and increased TRPC6 expression. Taken together, a novel AC068039.4/miR-26a-5p/TRPC6 axis may involves in the development of hypoxic pulmonary hypertension.

The neointimal and medial hypertrophy of the small and medium pulmonary arteries plays an essential role in PVR, mainly due to the excessive proliferation of PASMCs[26]. LncRNAs are endogenously RNAs lacking protein-encoding function with more than 200 nucleotide length, and were considered to be transcription junk before[8]. Multiple IncRNAs has been confirmed participating in the development of $\mathrm{PH}$ through the regulation of the proliferation of PASMCs and pulmonary vascular remodeling[27-30]. Benefit from the rapid development of next-generation sequencing technology, emerging IncRNAs have been discovered involved in the regulation of cardiovascular disease[31, 32]. Gu et al. firstly performed IncRNA expression profiles of lung tissues of 5 CTEPH patients and 5 healthy control tissues by microarray, and 185 differentially expressed IncRNAs were found[33]. Liu et al.[30] conducted a microarray analysis and found that 36 up-regulated IncRNAs and 111 down-regulated IncRNAs in the pulmonary arteries (PA) of HPH rats (fold change $>2.0$ and $\mathrm{P}$ value $<0.05$ ). TCONS_00034812 was identified remarkably reduced in PA of $\mathrm{HPH}$ rats (fold change $=8.97, \mathrm{P}=0.01$ ). While Kenny Schlosser demonstrated no significant changes of IncRNAs in plasma of PAH and healthy subjects[34]. Different from previous studies, in the current research, microarray analysis was conducted to find out the 
differently expressed IncRNAs in hypoxia and normoxia induced PASMCs. Significantly differential IncRNAs were selected for PCR verification, AC068039.4 was found 3 times higher in hypoxia induced PASMCs. Furthermore, down regulation of AC068039.4 suppressed the proliferation and migration of PASMCs induced by hypoxia, AC068039.4 also involved in cell cycle progression, knocking down AC068039.4 decreased the percentage of cells in the $S$ and G2/M phases through inhibition of PASMCs entering into $\mathrm{G} 1$ phrase.

Competing endogenous RNA (ceRNA) is one of the main mechanisms of IncRNA-miRNA interactions. LncRNAs function as miRNAs sponges or bait to isolate miRNAs through complementary base pairing, leading to the loss or reduction of miRNA function, further involves in post-transcriptional regulation[35]. CHRF was identified as endogenous sponge through downregulation of miR-489 to participate in the regulation of cardiac hypertrophy[36]. Furthermore, MALAT1 served as ceRNA through sponging miR-1243p. 1 and promoted proliferation and migration of PASMCs. MEG3 and H19 acted as miRNA sponges of miR-328 and miR-675 respectively in $\mathrm{PH}[37,12]$. In the current research, miR-26a expression was significantly down-regulated in hypoxia induced PASMCs. Luciferase reports assay confirmed the binding between AC068039.4 and miR-26a. We demonstrated that miR-26a is the target gene of AC068039.4, overexpression AC068039.4 promoted PASMCs proliferation through downregulation of miR-26a expression in hypoxia induced PASMCs.

The increase of free intracellular $\mathrm{Ca}^{2+}\left(\left[\mathrm{Ca}^{2+}\right]_{\mathrm{i}}\right)$ concentration is a vital factor to stimulate pulmonary vascular contraction and proliferation of PASMCs[38]. Store-operated $\mathrm{Ca}^{2+}$ canonical (SOCC) mediated store-operated calcium entry (SOCE) results to the imbalance of intracellular calcium in PASMCs under hypoxia, causing pulmonary artery contraction and remodeling[39]. SOCC is mainly composed of transient receptor potential canonical channel (TRPC) proteins[40], of which TRPC6 is a major protein constituting SOCC[41]. Previous research indicated that chronic hypoxia upregulate the expression of TRPC6 in pulmonary vein smooth muscle cells (PVSMCs) and $\left[\mathrm{Ca}^{2+}\right]_{\text {, }}$, and thereby promoted the proliferation and migration of PVSMC[19]. Ying Yu et al. demonstrated up-regulated TRPC6 expression promoted PASMCs proliferation isolated from IPAH patients[42]. Bosentan exerts a medicinal effect on PASMCs involves the downregulation of TRPC6 and inhibits the proliferation of PASMCs[43]. Gene sequencing revealed higher frequency of $-254(C \rightarrow G)$ of single nucleotide polymorphism (SNP) in TRPC6 promoter region in idiopathic PAH patients[44]. TRPC6 expression was significantly increased in hypoxia induced PASMCs, but the upstream regulatory mechanism of TRPC6 remains largely unknown.

microRNAs (miRNAs) are a class of highly conserved non-coding RNAs with 21 to 23 nucleotides, miRNAs exert their role through inhibition of downstream targeted mRNA or promotion of the degradation of targeted mRNAs via RNA interference[45]. miRNAs are essential in a variety of pathophysiological processes[46]. miR-26a is regarded as a tumor suppressor, it could inhibit lung cancer cell proliferation, migration and invasion[47]. The current research demonstrated knocking down AC068039.4 significantly down-regulated the expression of TRPC6 in PASMCs under hypoxia condition. Besides, PASMCs transfected with miR-26a-5p mimic could reverse the up-regulated TRPC6 induced by hypoxia, luciferase 
reports assay confirmed that miR-26a could bind to TRPC6 3'UTR, suggesting that miR-26a may be involved in the upstream regulation of TRPC6. Consistently, Schlosser K and his colleagues found circulating miR-26 decreased in plasma from PAH patients and monocrotaline (MCT)-induced PH rats, indicating that miR-26a may be a reliable potential biomarker of $\mathrm{PH}[18]$. Interestingly, studies have shown that overexpression of miR-26a can inhibit TRPC6 expression and related downstream apoptotic pathway activation, thereby participating in reversing ox-LDL-induced apoptosis[48]. Besides, miR-26a was downregulated in experimental atherosclerosis model both in vivo and in vitro via targeting TRPC3[49]. These data indicated that AC068039.4/miR-26a-5p/TRPC6 axis might participate in the development of hypoxic pulmonary hypertension.

\section{Conclusion}

In conclusion, the current research demonstrated that AC068039.4 is up-regulated in PASMCs induced by hypoxia, AC068039.4 promoted PASMCs proliferation, migration and cell cycle progression through competitively combining with miR-26a-5p through ceRNA pattern. Decreased free miR-26a-5p binded to the downstream target gene TRPC6, resulting in decreased degraded TRPC6 and increased TRPC6 expression and contributing to increased SOCE and $\left[\mathrm{Ca}^{2}{ }^{+}\right]_{i}$ level, ultimately promoting the proliferation and migration of PASMCs, eventually contributing to pulmonary vascular remodeling. Figure 6 illustrated that AC068039.4 /miR-26a-5p/TRPC6 axis plays a significant role in the regulation of hypoxia induced PASMCs proliferation, it might provide a novel potential therapeutic insight for the treatment of HPH.

\section{Abbreviations}

CCK-8: Cell counting kit-8; CeRNA: Competing endogenous RNA; FBS: Fetal bovine serum; HPH: Hypoxic pulmonary hypertension; LncRNA: Long non-coding RNA; MCT: Monocrotaline; miRNAs: microRNAs; PAs: Pulmonary arteries; PASMCs: Pulmonary artery smooth muscle cells; PVR: Pulmonary vascular remodeling; PVSMCs: Pulmonary vein smooth muscle cells; qRT-PCR: Quantitative real time polymerase chain reaction; SNP: Single nucleotide polymorphism; SOCC: Store-operated $\mathrm{Ca}^{2+}$ canonical; SOCE: Storeoperated calcium entry; TRPC6: Transient receptor potential canonical 6; UTR: Untranslated region;

\section{Declarations}

\section{Acknowledgements}

We thanked all subjects who participated in this study.

\section{Funding}

This work was supported by National Natural Science Foundation of China under Grant No. 81600227 and 81970237.

\section{Availability of data and materials}


The datasets used and analyzed during the current study are available from the corresponding author on reasonable request.

\section{Authors' contributions}

$Y Q, B Z, G Y, D W, Y Q$ contributed to the conception and design of the work. YQ, BZ and LL performed the experiments, analyzed the data, and made the figures; $Y Q, B L, E L, J H$ analyzed the results; $Y Q$ drafted the paper. CT revised the work critically. All authors read and approved the final manuscript.

\section{Ethics approval and consent to participate}

This study was authorized by the Zhongda Hospital, and obtained written informed consents from all the participants.

\section{Consent for publication}

Not applicable.

\section{Competing interests}

The authors declare that they have no competing interests.

\section{References}

1. Galie N, Humbert M, Vachiery JL, Gibbs S, Lang I, Torbicki A, Simonneau G, Peacock A, Vonk Noordegraaf A, Beghetti M, Ghofrani A, Gomez Sanchez MA, Hansmann G, Klepetko W, Lancellotti P, Matucci M, McDonagh T, Pierard LA, Trindade PT, Zompatori M, Hoeper M. 2015 Esc/Ers Guidelines for the Diagnosis and Treatment of Pulmonary Hypertension: The Joint Task Force for the Diagnosis and Treatment of Pulmonary Hypertension of the European Society of Cardiology (Esc) and the European Respiratory Society (Ers): Endorsed By: Association for European Paediatric and Congenital Cardiology (Aepc), International Society for Heart and Lung Transplantation (Ishlt). Eur Heart J. 2016;37:67-119.

2. Newman JH, Fanburg BL, Archer SL, Badesch DB, Barst RJ, Garcia JG, Kao PN, Knowles JA, Loyd JE, McGoon MD, Morse JH, Nichols WC, Rabinovitch M, Rodman DM, Stevens T, Tuder RM, Voelkel NF, Gail DB. Pulmonary Arterial Hypertension: Future Directions: Report of a National Heart, Lung and Blood Institute/Office of Rare Diseases Workshop. Circulation. 2004;109:2947-52.

3. Chang YT, Tseng CN, Tannenberg P, Eriksson L, Yuan K, de Jesus Perez VA, Lundberg J, Lengquist M, Botusan IR, Catrina SB, Tran PK, Hedin U, Tran-Lundmark K. Perlecan Heparan Sulfate Deficiency Impairs Pulmonary Vascular Development and Attenuates Hypoxic Pulmonary Hypertension. Cardiovasc Res. 2015;107:20-31.

4. Thenappan T, Ormiston ML, Ryan JJ, Archer SL. Pulmonary Arterial Hypertension: Pathogenesis and Clinical Management. BMJ. 2018;360:j5492. 
5. Galie N, Barbera JA, Frost AE, Ghofrani HA, Hoeper MM, McLaughlin VV, Peacock AJ, Simonneau G, Vachiery JL, Grunig E, Oudiz RJ, Vonk-Noordegraaf A, White RJ, Blair C, Gillies H, Miller KL, Harris JH, Langley J, Rubin LJ. Initial Use of Ambrisentan Plus Tadalafil in Pulmonary Arterial Hypertension. N Engl J Med. 2015;373:834-44.

6. Hoeper MM, Ghofrani HA, Grunig E, Klose H, Olschewski H, Rosenkranz S. Pulmonary Hypertension. Dtsch Arztebl Int. 2017;114:73-84.

7. St Laurent G, Wahlestedt C, Kapranov P. The Landscape of Long Noncoding Rna Classification. Trends Genet. 2015;31:239-51.

8. Huarte M. The Emerging Role of Lncrnas in Cancer. Nat Med. 2015;21:1253-61.

9. Mercer TR, Mattick JS. Structure and Function of Long Noncoding Rnas in Epigenetic Regulation. Nat Struct Mol Biol. 2013;20:300-7.

10. Salmena L, Poliseno L, Tay Y, Kats L, Pandolfi PP. A Cerna Hypothesis: The Rosetta Stone of a Hidden Rna Language? Cell. 2011;146:353-8.

11. Yoon JH, Abdelmohsen K, Gorospe M. Functional Interactions among Micrornas and Long Noncoding Rnas. Semin Cell Dev Biol. 2014;34:9-14.

12. Xing Y, Zheng X, Fu Y, Qi J, Li M, Ma M, Wang S, Li S, Zhu D. Long Noncoding Rna-Maternally Expressed Gene 3 Contributes to Hypoxic Pulmonary Hypertension. Mol Ther. 2019;27:2166-81.

13. Chen J, Guo J, Cui X, Dai Y, Tang Z, Qu J, Raj JU, Hu Q, Gou D. The Long Noncoding Rna Lnrpt Is Regulated by Pdgf-Bb and Modulates the Proliferation of Pulmonary Artery Smooth Muscle Cells. Am J Respir Cell Mol Biol. 2018;58:181-93.

14. Wang S, Cao W, Gao S, Nie X, Zheng X, Xing Y, Chen Y, Bao H, Zhu D. Tug1 Regulates Pulmonary Arterial Smooth Muscle Cell Proliferation in Pulmonary Arterial Hypertension. Can J Cardiol. 2019;35:1534-45.

15. Wang D, Xu H, Wu B, Jiang S, Pan H, Wang R, Chen J. Long Noncoding Rna Malat1 Sponges Mir1243p.1/KIf5 to Promote Pulmonary Vascular Remodeling and Cell Cycle Progression of Pulmonary Artery Hypertension. Int J Mol Med. 2019;44:871-84.

16. Zhang H, Liu Y, Yan L, Wang S, Zhang M, Ma C, Zheng X, Chen H, Zhu D. Long Noncoding Rna Hoxaas3 Contributes to Hypoxia-Induced Pulmonary Artery Smooth Muscle Cell Proliferation. Cardiovasc Res. 2019;115:647-57.

17. Leisegang MS, Fork C, Josipovic I, Richter FM, Preussner J, Hu J, Miller MJ, Epah J, Hofmann P, Gunther S, Moll F, Valasarajan C, Heidler J, Ponomareva Y, Freiman TM, Maegdefessel L, Plate KH, Mittelbronn M, Uchida S, Kunne C, Stellos K, Schermuly RT, Weissmann N, Devraj K, Wittig I, Boon RA, Dimmeler S, Pullamsetti SS, Looso M, Miller FJ, Jr., Brandes RP. Long Noncoding Rna Mantis Facilitates Endothelial Angiogenic Function. Circulation. 2017;136:65-79.

18. Schlosser K, White RJ, Stewart DJ. Mir-26a Linked to Pulmonary Hypertension by Global Assessment of Circulating Extracellular Micrornas. Am J Respir Crit Care Med. 2013;188:1472-5.

19. Wang Q, Wang D, Yan G, Sun L, Tang C. Trpc6 Is Required for Hypoxia-Induced Basal Intracellular Calcium Concentration Elevation, and for the Proliferation and Migration of Rat Distal Pulmonary 
Venous Smooth Muscle Cells. Mol Med Rep. 2016;13:1577-85.

20. Weissmann N, Dietrich A, Fuchs B, Kalwa H, Ay M, Dumitrascu R, Olschewski A, Storch U, Mederos y Schnitzler M, Ghofrani HA, Schermuly RT, Pinkenburg O, Seeger W, Grimminger F, Gudermann T. Classical Transient Receptor Potential Channel 6 (Trpc6) Is Essential for Hypoxic Pulmonary Vasoconstriction and Alveolar Gas Exchange. Proc Natl Acad Sci USA. 2006;103:19093-8.

21. Fernandez RA, Wan J, Song S, Smith KA, Gu Y, Tauseef M, Tang H, Makino A, Mehta D, Yuan JX. Upregulated Expression of Stim2, Trpc6, and Orai2 Contributes to the Transition of Pulmonary Arterial Smooth Muscle Cells from a Contractile to Proliferative Phenotype. Am J Physiol Cell Physiol. 2015;308:C581-93.

22. Zou ZQ, Xu J, Li L, Han YS. Down-Regulation of Sencr Promotes Smooth Muscle Cells Proliferation and Migration in Db/Db Mice through up-Regulation of Foxo1 and Trpc6. Biomed Pharmacother. 2015;74:35-41.

23. Acosta-Iborra B, Tiana M, Maeso-Alonso L, Hernandez-Sierra R, Herranz G, Santamaria A, Rey C, Luna R, Puente-Santamaria L, Marques MM, Marin MC, Del Peso L, Jimenez B. Hypoxia Compensates Cell Cycle Arrest with Progenitor Differentiation During Angiogenesis. Faseb j. 2020.

24. Liu Y, Ma C, Zhang Q, Yu L, Ma J, Zhang L, Hao X, Cao F, Wang L, Zhu D. The Key Role of Transforming Growth Factor-Beta Receptor I and 15-Lipoxygenase in Hypoxia-Induced Proliferation of Pulmonary Artery Smooth Muscle Cells. Int J Biochem Cell Biol. 2012;44:1184-202.

25. Liu B, Wang D, Luo E, Hou J, Qiao Y, Yan G, Wang Q, Tang C. Role of Tg2-Mediated Serca2 Serotonylation on Hypoxic Pulmonary Vein Remodeling. Front Pharmacol. 2019;10:1611.

26. Farber HW, Loscalzo J. Pulmonary Arterial Hypertension. N Engl J Med. 2004;351:1655-65.

27. Su H, Xu X, Yan C, Shi Y, Hu Y, Dong L, Ying S, Ying K, Zhang R. Lncrna H19 Promotes the Proliferation of Pulmonary Artery Smooth Muscle Cells through At1r Via Sponging Let-7b in Monocrotaline-Induced Pulmonary Arterial Hypertension. Respir Res. 2018;19:254.

28. Yang L, Liang H, Shen L, Guan Z, Meng X. Lncrna Tug1 Involves in the Pulmonary Vascular Remodeling in Mice with Hypoxic Pulmonary Hypertension Via the Microrna-374c-Mediated Foxc1. Life Sci. 2019;237:116769.

29. Gong J, Chen Z, Chen Y, Lv H, Lu H, Yan F, Li L, Zhang W, Shi J. Long Non-Coding Rna Casc2 Suppresses Pulmonary Artery Smooth Muscle Cell Proliferation and Phenotypic Switch in HypoxiaInduced Pulmonary Hypertension. Respir Res. 2019;20:53.

30. Liu Y, Sun Z, Zhu J, Xiao B, Dong J, Li X. Lncrna-Tcons_00034812 in Cell Proliferation and Apoptosis of Pulmonary Artery Smooth Muscle Cells and Its Mechanism. J Cell Physiol. 2018;233:4801-14.

31. Yao Q-P, Xie Z-W, Wang K-X, Zhang P, Han Y, Qi Y-X, Jiang Z-L. Profiles of Long Noncoding Rnas in Hypertensive Rats: Long Noncoding Rna Xr007793 Regulates Cyclic Strain-Induced Proliferation and Migration of Vascular Smooth Muscle Cells. J Hypertens. 2017;35:1195-203.

32. Wang Y-N-Z, Shan K, Yao M-D, Yao J, Wang J-J, Li X, Liu B, Zhang Y-Y, Ji Y, Jiang Q, Yan B. Long Noncoding Rna-Gas5: A Novel Regulator of Hypertension-Induced Vascular Remodeling. Hypertension. 2016;68:736-48. 
33. Gu S, Li G, Zhang X, Yan J, Gao J, An X, Liu Y, Su P. Aberrant Expression of Long Noncoding Rnas in Chronic Thromboembolic Pulmonary Hypertension. Mol Med Rep. 2015;11:2631-43.

34. Schlosser K, Hanson J, Villeneuve PJ, Dimitroulakos J, Mclntyre L, Pilote L, Stewart DJ. Assessment of Circulating Lncrnas under Physiologic and Pathologic Conditions in Humans Reveals Potential Limitations as Biomarkers. Sci Rep. 2016;6:36596.

35. Jin Q, Zhao Z, Zhao Q, Yu X, Yan L, Zhang Y, Luo Q, Liu Z. Long Noncoding Rnas: Emerging Roles in Pulmonary Hypertension. Heart Fail Rev. 2019.

36. Wang K, Liu F, Zhou LY, Long B, Yuan SM, Wang Y, Liu CY, Sun T, Zhang XJ, Li PF. The Long Noncoding Rna Chrf Regulates Cardiac Hypertrophy by Targeting Mir-489. Circ Res. 2014;114:137788.

37. Wang R, Zhou S, Wu P, Li M, Ding X, Sun L, Xu X, Zhou X, Zhou L, Cao C, Fei G. Identifying Involvement of H19-Mir-675-3p-Igf1r and H19-Mir-200a-Pdcd4 in Treating Pulmonary Hypertension with Melatonin. Mol Ther Nucleic Acids. 2018;13:44-54.

38. Stenmark KR, Mecham RP. Cellular and Molecular Mechanisms of Pulmonary Vascular Remodeling. Annu Rev Physiol. 1997;59:89-144.

39. Jiang Q, Lu W, Yang K, Hadadi C, Fu X, Chen Y, Yun X, Zhang J, Li M, Xu L, Tang H, Yuan JX, Wang J, Sun D. Sodium Tanshinone lia Sulfonate Inhibits Hypoxia-Induced Enhancement of Soce in Pulmonary Arterial Smooth Muscle Cells Via the Pkg-Ppar-Gamma Signaling Axis. Am J Physiol Cell Physiol. 2016;311:C136-49.

40. Qu YY, Wang LM, Zhong H, Liu YM, Tang N, Zhu LP, He F, Hu QH. Trpc1 Stimulates Calciumsensing Receptorinduced Storeoperated Ca2+ Entry and Nitric Oxide Production in Endothelial Cells. Mol Med Rep. 2017;16:4613-9.

41. Yang XR, Lin MJ, Sham JS. Physiological Functions of Transient Receptor Potential Channels in Pulmonary Arterial Smooth Muscle Cells. Adv Exp Med Biol. 2010;661:109-22.

42. Yu Y, Fantozzi I, Remillard CV, Landsberg JW, Kunichika N, Platoshyn O, Tigno DD, Thistlethwaite PA, Rubin LJ, Yuan JX. Enhanced Expression of Transient Receptor Potential Channels in Idiopathic Pulmonary Arterial Hypertension. Proc Natl Acad Sci USA. 2004;101:13861-6.

43. Kunichika N, Landsberg JW, Yu Y, Kunichika H, Thistlethwaite PA, Rubin LJ, Yuan JX. Bosentan Inhibits Transient Receptor Potential Channel Expression in Pulmonary Vascular Myocytes. Am J Respir Crit Care Med. 2004;170:1101-7.

44. Yu Y, Keller SH, Remillard CV, Safrina O, Nicholson A, Zhang SL, Jiang W, Vangala N, Landsberg JW, Wang JY, Thistlethwaite PA, Channick RN, Robbins IM, Loyd JE, Ghofrani HA, Grimminger F, Schermuly RT, Cahalan MD, Rubin LJ, Yuan JX. A Functional Single-Nucleotide Polymorphism in the Trpc6 Gene Promoter Associated with Idiopathic Pulmonary Arterial Hypertension. Circulation. 2009;119:2313-22.

45. Bartel DP. Micrornas: Target Recognition and Regulatory Functions. Cell. 2009;136:215-33.

46. Eulalio A, Huntzinger E, Izaurralde E. Getting to the Root of Mirna-Mediated Gene Silencing. Cell. 2008;132:9-14. 
47. Zhang X, Xiao D, Wang Z, Zou Y, Huang L, Lin W, Deng Q, Pan H, Zhou J, Liang C, He J. Microrna26a/B Regulate DNA Replication Licensing, Tumorigenesis, and Prognosis by Targeting Cdc6 in Lung Cancer. Mol Cancer Res. 2014;12:1535-46.

48. Zhang Y, Qin W, Zhang L, Wu X, Du N, Hu Y, Li X, Shen N, Xiao D, Zhang H, Li Z, Zhang Y, Yang H, Gao F, Du Z, Xu C, Yang B. Microrna-26a Prevents Endothelial Cell Apoptosis by Directly Targeting Trpc6 in the Setting of Atherosclerosis. Sci Rep. 2015;5:9401.

49. Feng M, Xu D, Wang L. Mir-26a Inhibits Atherosclerosis Progression by Targeting Trpc3. Cell Biosci. 2018;8:4.

\section{Figures}




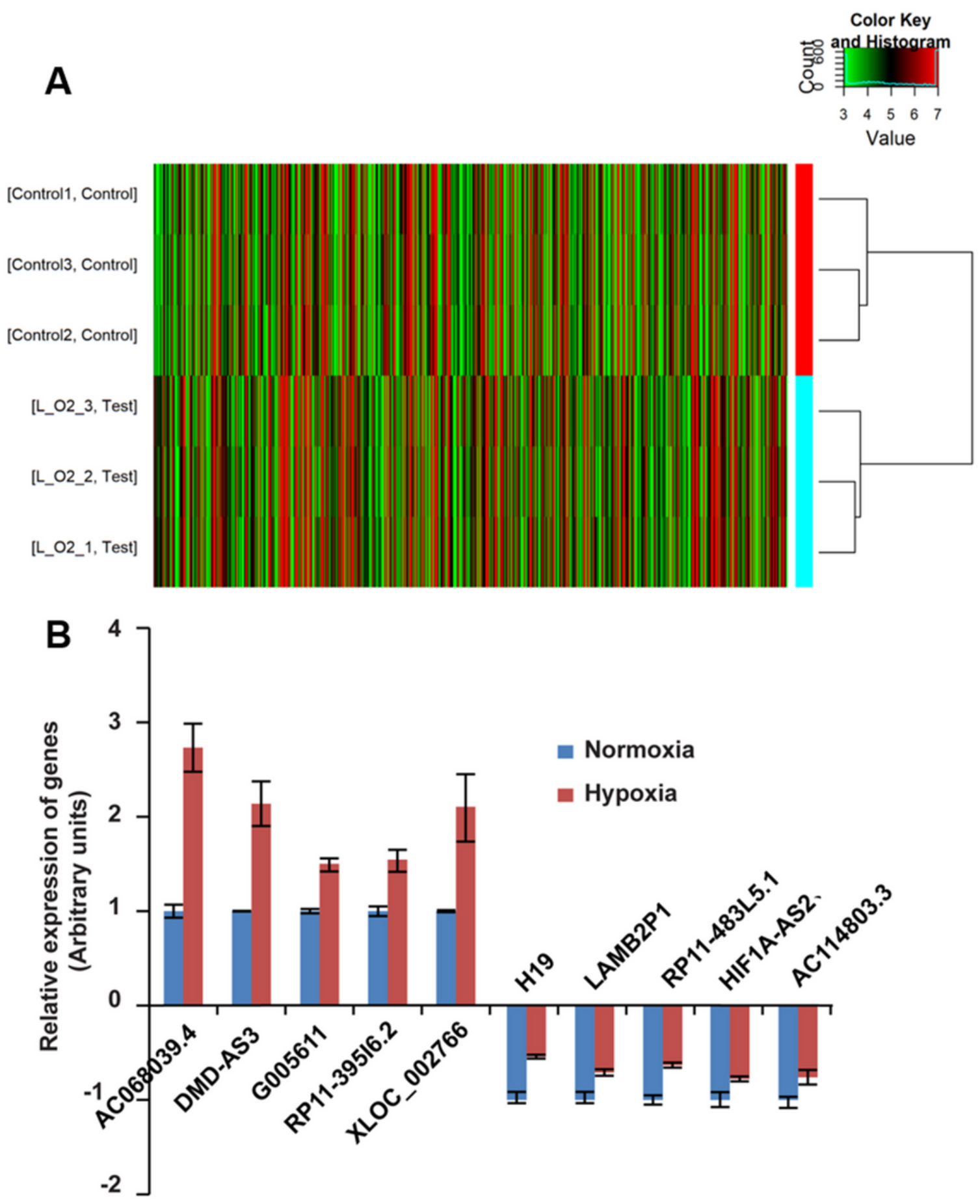

Figure 1

Differentially expressed profiles of IncRNAs in PASMCs cultured under normoxia and hypoxia. (A) The hierarchical clustering of differentially expressed IncRNAs. 1211 differentially expressed IncRNAs (698 up-regulated and 513 down-regulated) from hierarchical clustering were identified between normoxia and hypoxia induced PASMCs. The expression level of IncRNA is expressed in red if it is above the average value of the gene in all samples. Conversely, green indicates that the expression level of IncRNA is below 
the average value. B: Realtime-PCR validates significantly differently expressed IncRNAs, and IncRNA AC068039.4 significantly up-regulated in hypoxia-induced PASMCs.

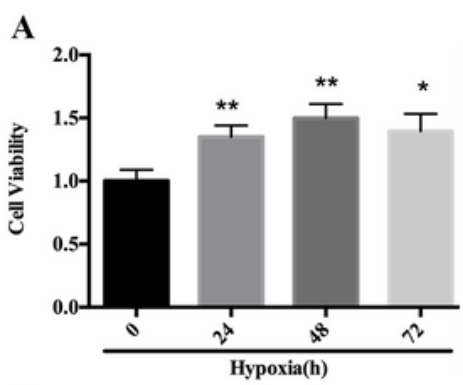

C

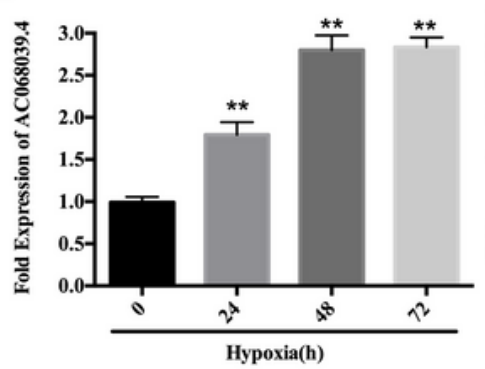

$\mathbf{E}$

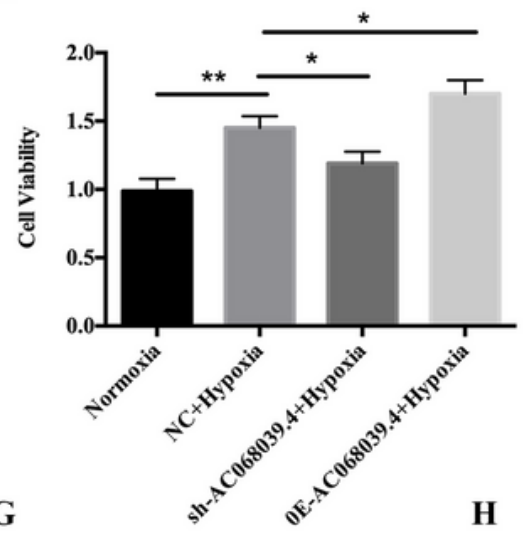

H
B

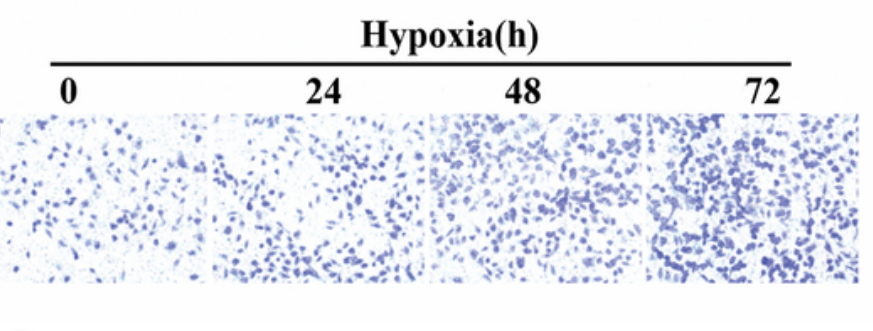

D

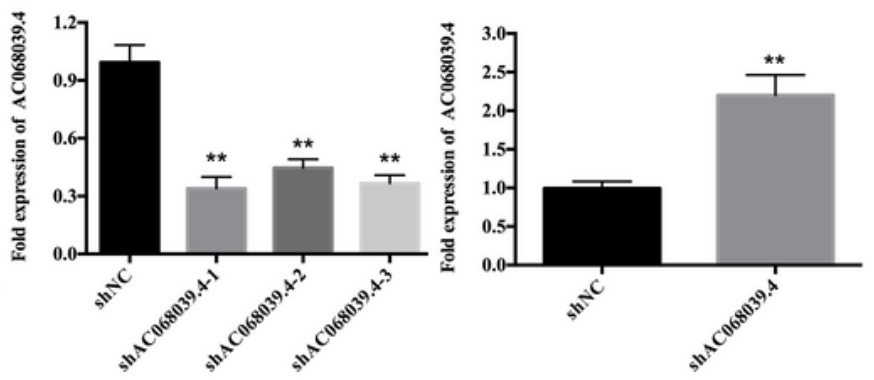

$\mathbf{F}$
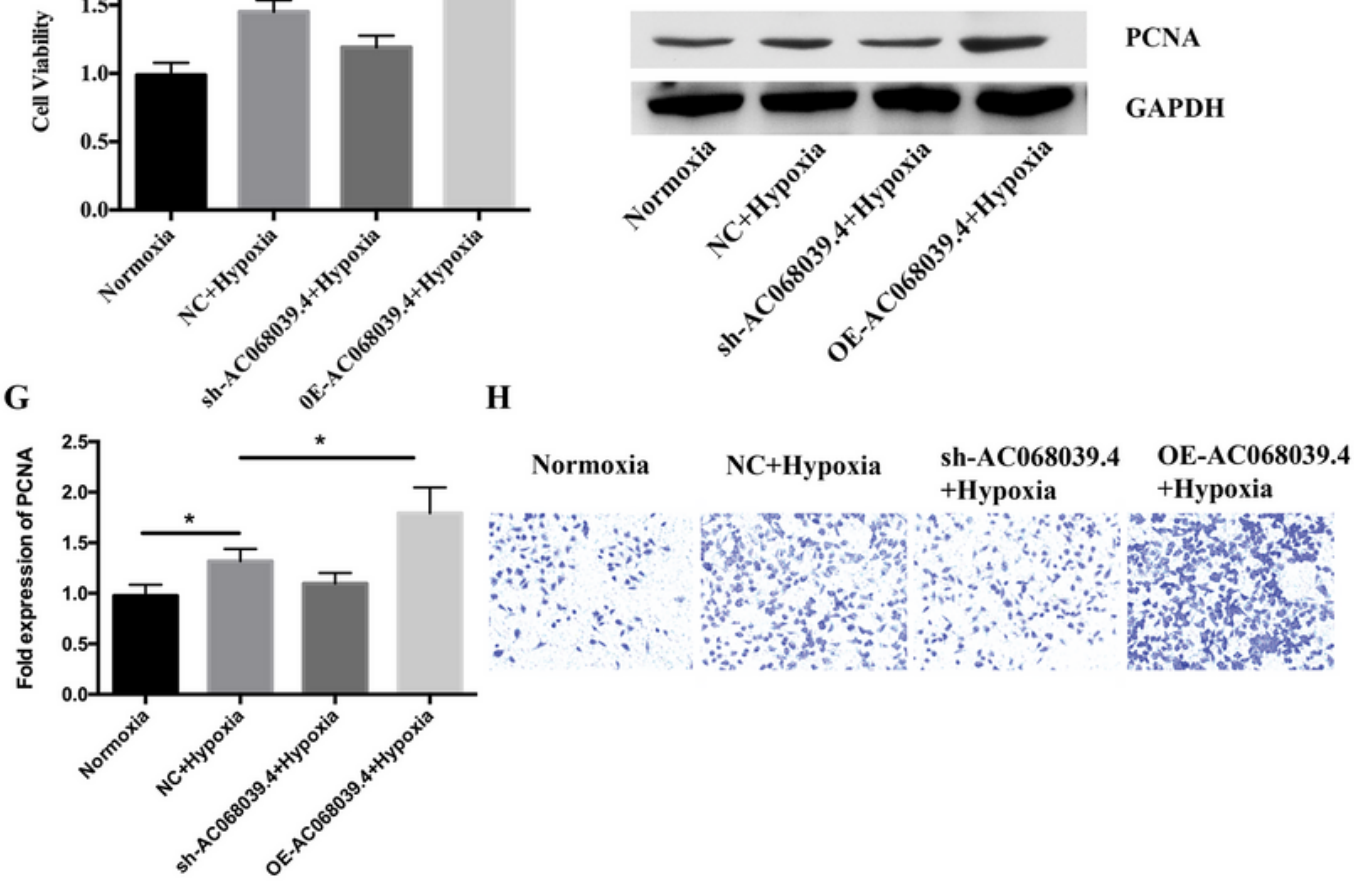

Figure 2

Down-regulation of AC068039.4 alleviated hypoxia-induced PASMCs proliferation and migration. (A) CCK8 assay analysis of PASMCs proliferation capacity after hypoxia exposure $0,24,48$, and 72 hours. (B) Transwell chamber analysis of the migration potential of PASMCs cultured at 0, 24, 48, and 72 hours 
of hypoxia. (C) Quantitative PCR of AC068039.4 in PASMCs after 24, 48 and 72h exposure to hypoxia compared with the normoxic group. (D) qPCR analysis of validity of shRNA lentivirus against AC068039.4 and lentivirus overexpressing AC068039.4. (E) CCK8 assay analysis of PASMCs proliferation capacity transfected with sh-AC068039.4 and OE-AC068039.4 respectively. (F) PCNA protein level and PCNA mRNA level(G) in hypoxia induced PASMCs model transfected with sh-AC068039.4 and OEAC068039.4. $(\mathrm{H})$ Transwell chamber analysis of migration potential of PASMCs transfected with sh- and OE-AC068039.4 Each experiment was repeated at least three times. * indicates statistical difference $(P<0.05)$ and ** represents $P<0.01$.

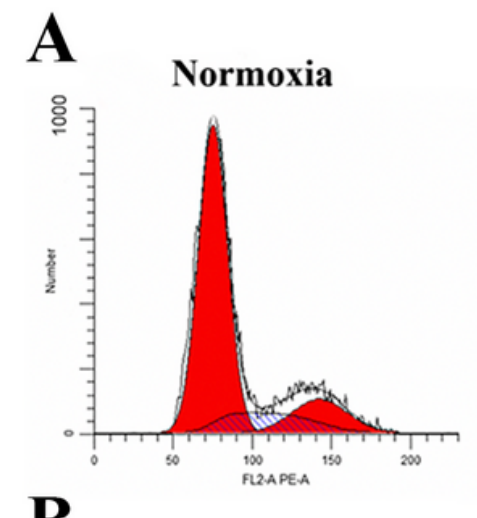

B

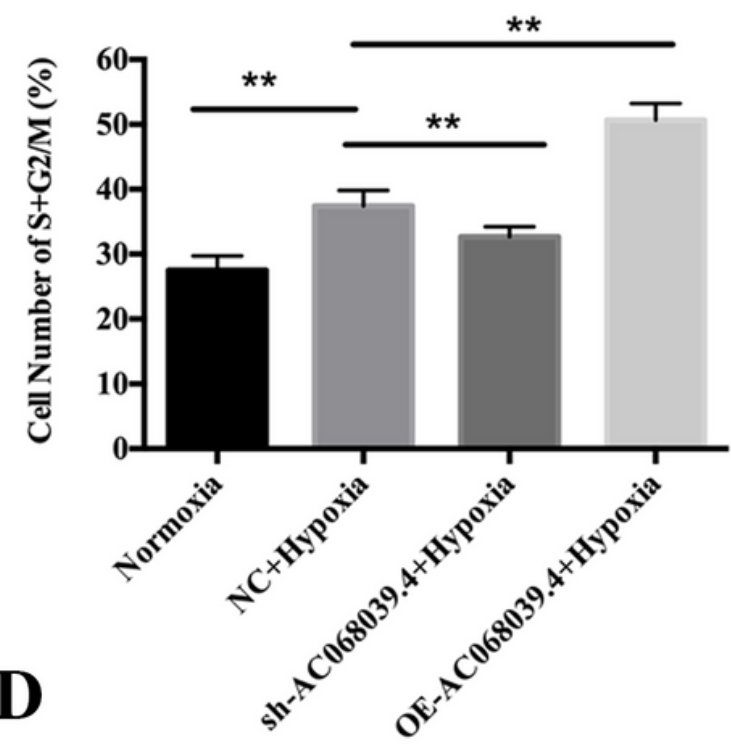

NC+Hypoxia

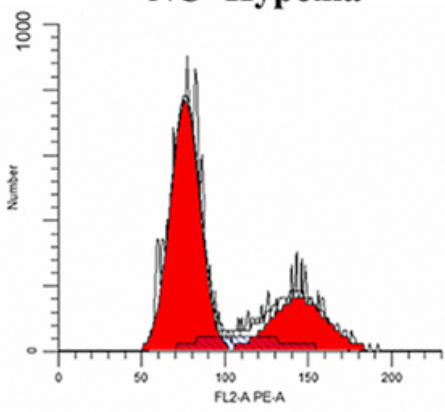

C
sh-AC068039.4+Hypoxia OE-AC068039.4+Hypoxia
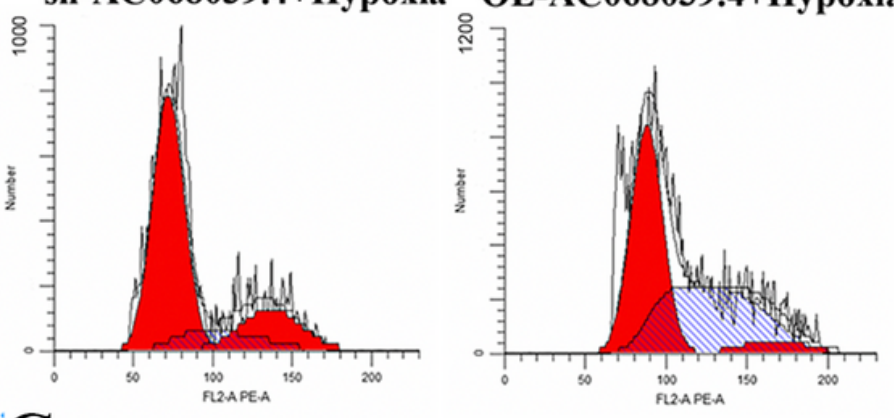
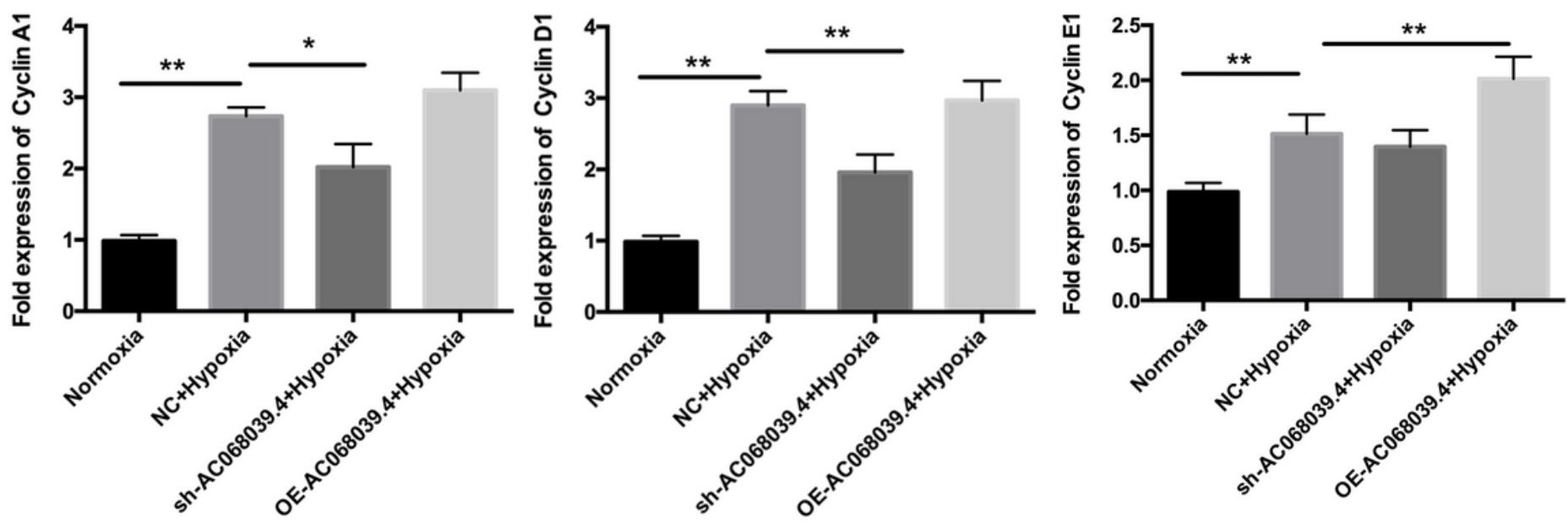
Figure 3

AC068039.4 was involved in hypoxia-induced PASMCs cell cycle progression. (A) Cell cycle distribution was assessed by flow cytometry and analyzed quantitatively (B). (C) Protein expression levels of cyclin A1, cyclin D1 and cyclin E1 were analyzed by western blotting following transfection with sh-AC068039.4 and OE-AC068039.4. (D) mRNA level of cyclin A1, cyclin D1 and cyclin E1 were analyzed by qPCR following transfection with sh-AC068039.4 and OE-AC068039.4. * and ** represent $P<0.05, P<0.01$ respectively.

A

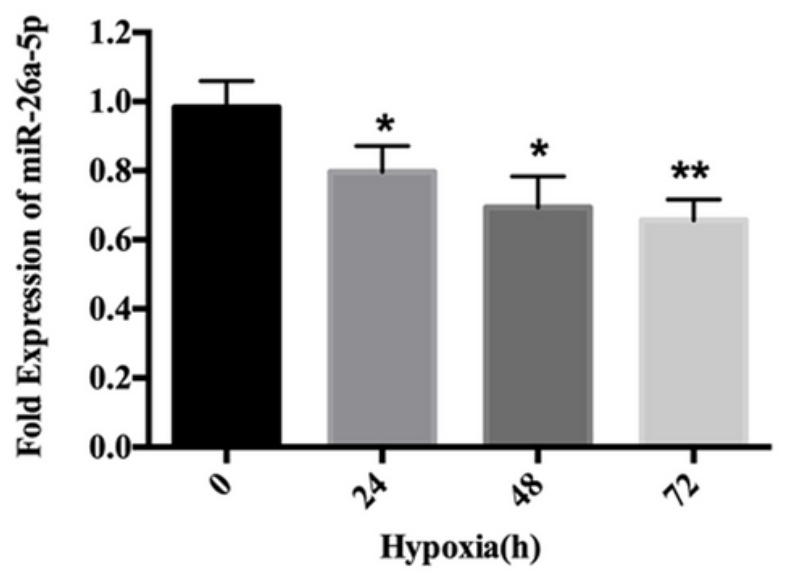

C

AC068039.4-WT

$\mathbf{E}$

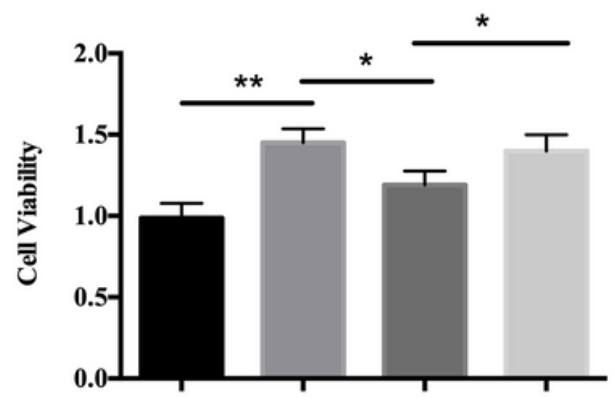

B

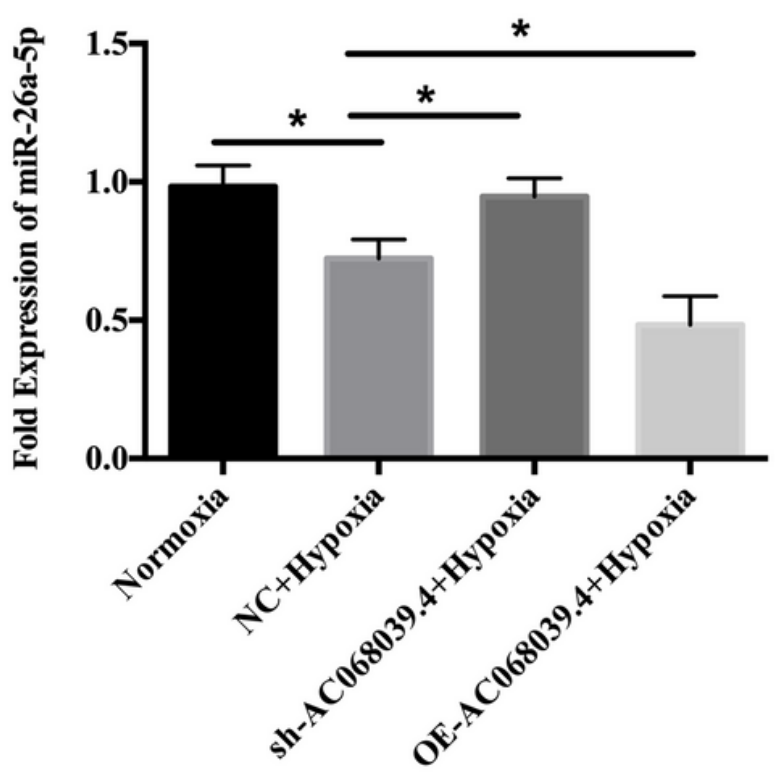

Hypoxia

shNC

sh-AC068039.4

miR-26a-5p inhibitor
Gene sequence constructed into vector

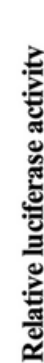
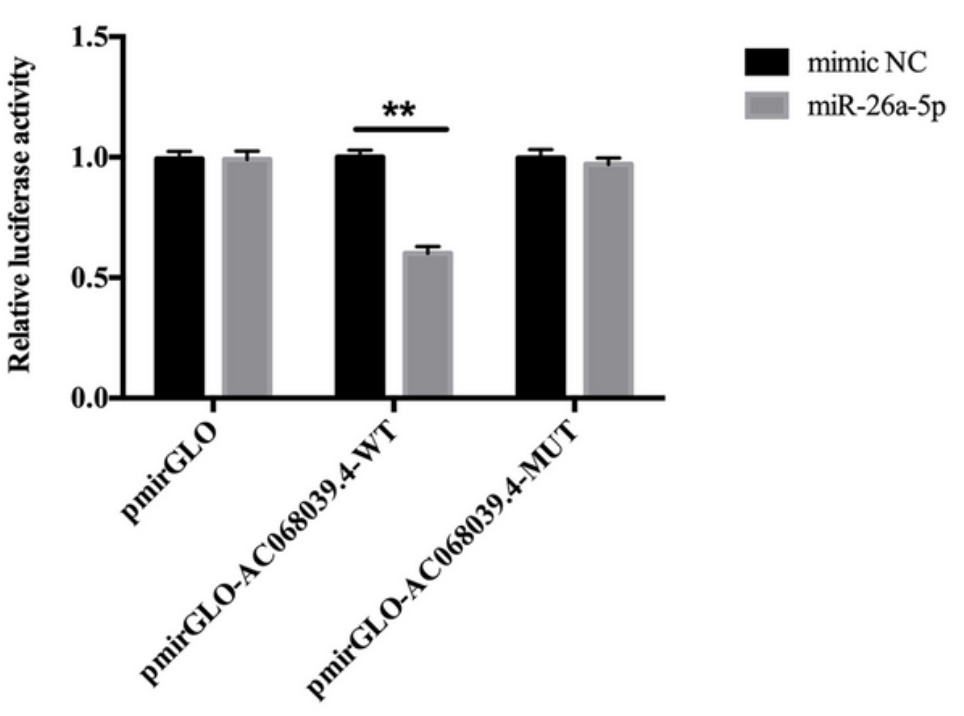

5 '...ATATAGACATTTTAAATAAATTGCT GTACTTGACCAAATAATGCCATGTGT GAAAGTAGT...3'

5 ...ATATAGACATTTTAAATAAATT GAAAGTAGT...3'

D 


\section{Figure 4}

AC068039.4 sponges to miR-26a-5p and promoted hypoxic PASMCs proliferation. (A) qRT-PCR analysis of miR-26-5p expression levels in hypoxia induced PASMCs at different hypoxia exposure time. (B) Expression of miR-26a-5p in PASMCs transfected with sh-AC068039.4, OE-AC068039.4 and negative control. (C) Gene sequence of wild type AC068039.4 and mutated AC068039.4 constructed into vector in luciferase reporter assay analysis. (D) Luciferase reporter assay analysis of the binding between miR26a-5p and predicted binding sites in AC068039.4. (E) CCK8 assay analysis of the cell proliferation viability in hypoxia induced PASMCs transfected with sh-AC068039.4, miR-21 inhibitor and NC respectively. * and ** represent $\mathrm{P}<0.05, \mathrm{P}<0.01$ respectively. 
A

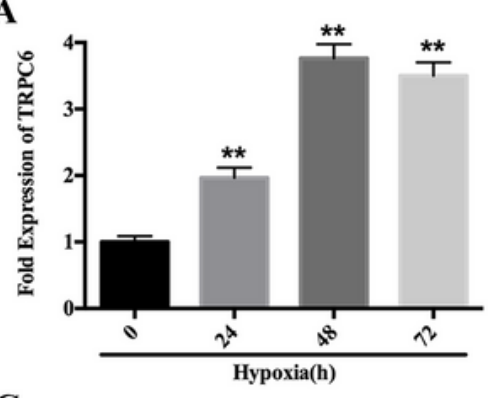

C

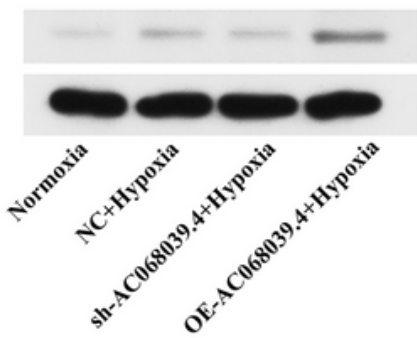

E

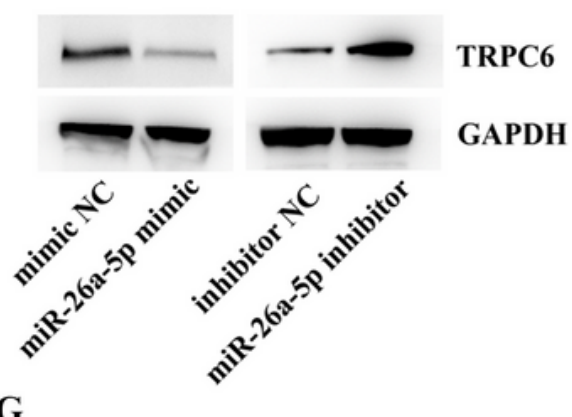

B

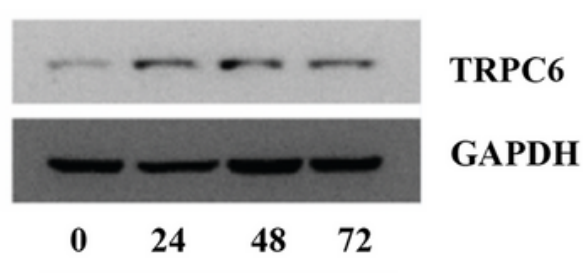

Hypoixa(h)

D
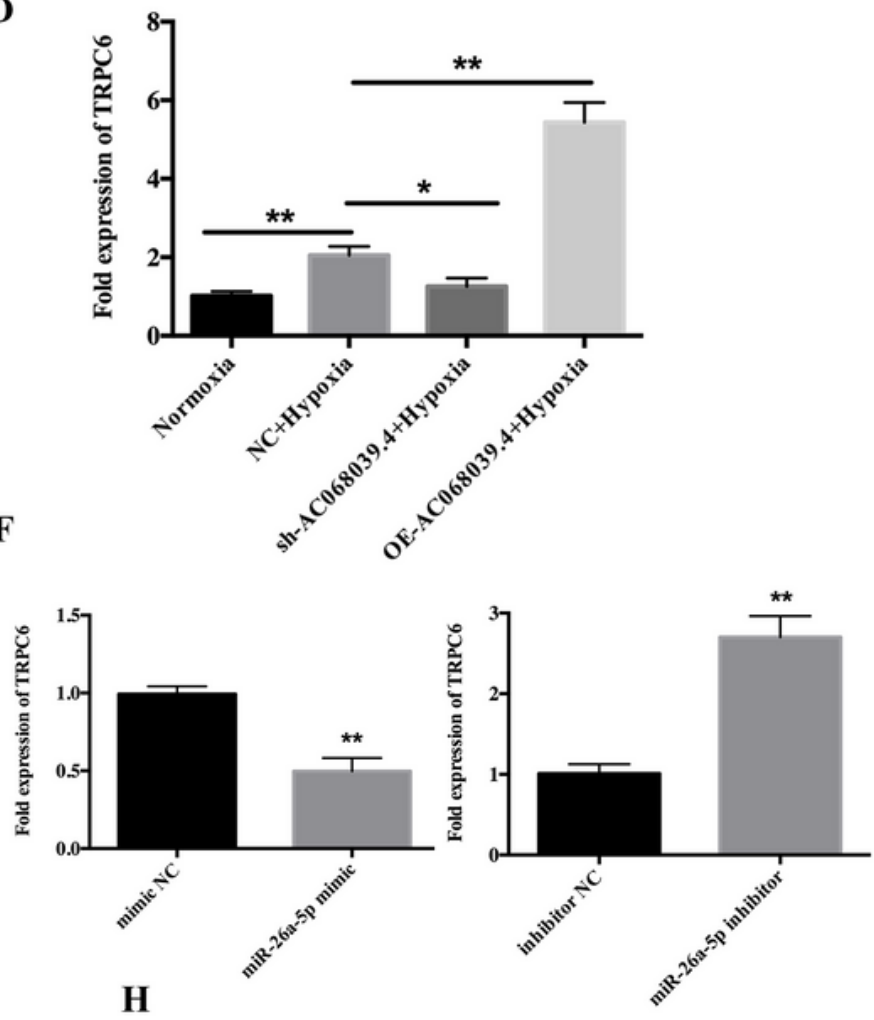

H

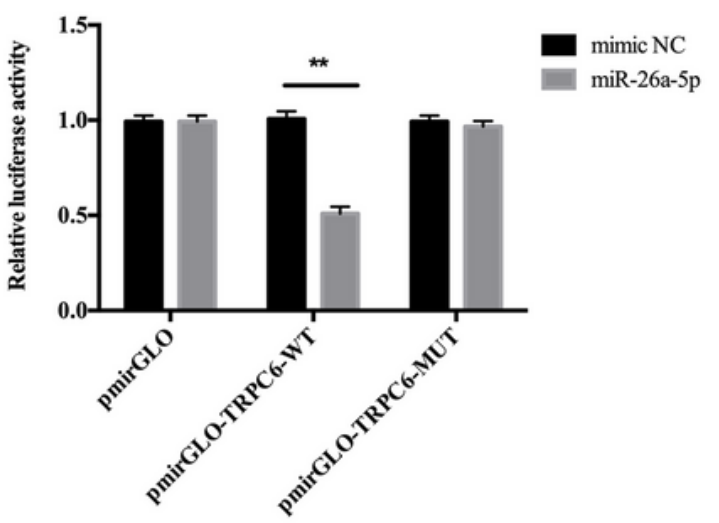

\section{Figure 5}

AC068039.4 promoted hypoxic PASMCs proliferation through AC068039.4/miR-26a-5p/TRPC6 axis. (A)TRPC6 mRNA level in PASMCs exposure to hypoxia. (B)The expression of TRPC6 protein in hypoxia induced PASMC. The expression of TRPC6 protein level (C) and TRPC6 mRNA (D) in PASMCs transfected with sh-AC068039.4 OE-AC068039.4 and negative control. TRPC6 protein expression (E) and TRPC6 mRNA expression (F) in PASMCs transfected with miR-26a-5p mimic, mimic NC, miR-26a-5p inhibitor and 
inhibitor NC. (G) The binding site between miR-26a-5p and TRPC6 mRNA 3'UTR predicted by bioinformatics software. $(\mathrm{H})$ Luciferase reporter assay analysis of the binding between miR-26a-5p and predicted binding sites in TRPC6. * and ** represent $P<0.05, P<0.01$ respectively.

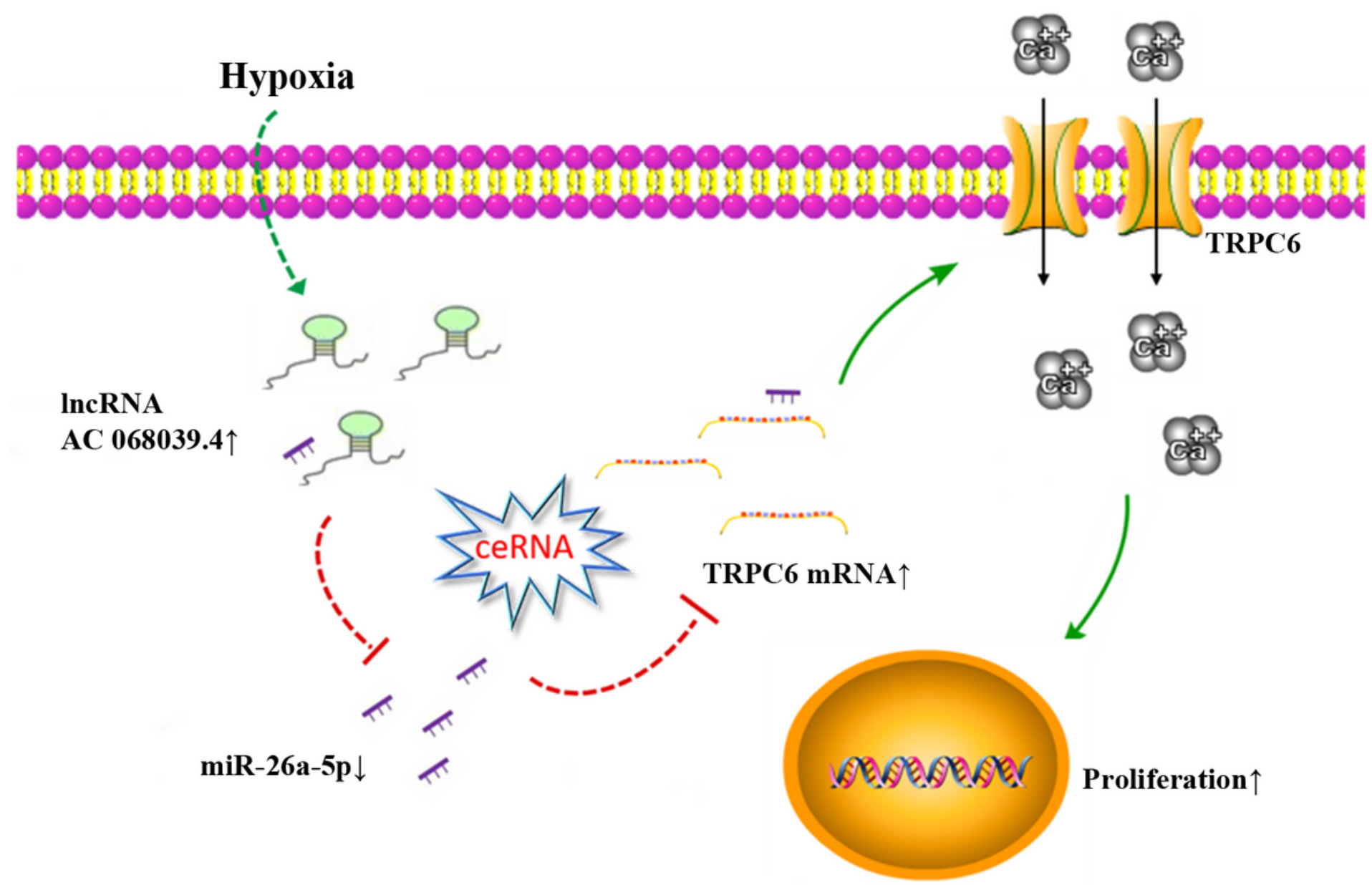

\section{Figure 6}

Working model: the activation of the AC068039.4/miR-26a-5p/TRPC6 axis plays a vital role in hypoxia induced PASMCs proliferation. AC068039.4 is up-regulated in PASMCs exposed to hypoxia, AC068039.4 promotes PASMCs proliferation, migration and cell cycle. AC068039.4 competitively binds miR-654-3p through ceRNA model, leading to reduced binding between free miR-654-3p and target TRPC6 mRNA. Increased expression of TRPC6 mediates the increase of SOCE, which promotes PASMCs proliferation and migration, eventually causing Pulmonary vascular remodeling. 